STUDIA ROSSICA POSNANIENSIA, vol. XL, cz. 2: 2015, pp. 121-128. ISBN 978-83-232-2934-6. ISSN 0081-6884. Adam Mickiewicz University Press, Poznań

\title{
СЕМАНТИЧЕСКАЯ СТРУКТУРА ПРИЛАГАТЕЛЬНЫХ БЕЛЬЙИВІАЕ В РУССКОМ И ПОЛЬСКОМ ЯЗЫКАХ
}

\author{
SEMANTIC STRUCTURE OF THE ADJECTIVES \\ БЕЛЫЙ AND ВIAЄ $Y$ IN POLISH AND RUSSIAN
}

\author{
АНДЖЕЙ НАРЛОХ
}

\begin{abstract}
This article attempts to describe the semantic structure of the adjective biaty in the Polish language and the adjective белыи in the Russian language. Following R. Tokarski's theory, according to which the semantics of the white color can be interpreted in two ways, the author puts forward a hypothesis that there is a third way to interpret the semantics of this adjective, i.e. the so-called transparent interpretation of white. The analysis uses lexicographic data that were obtained from contemporary dictionaries of both languages.
\end{abstract}

Andrzej Narloch, Uniwersytet im. Adama Mickiewicza w Poznaniu, Poznań - Polska.

Лексика цвета рассматривается в современном языкознании через призму взаимодействия языка и культуры ${ }^{1}$. Функционирование цветообозначений обусловливается их культурной отмеченностью. Язык каждого этноса моделирует специфику употребления и восприятия цветов. Каждый народ выработал свое видение цвета, символику, и по-своему дешифрует цвет.

На рубеже XX и XXI веков особую популярность снискали работы, посвященные семантическому аспекту цветообозначений. Лнгвистами реконструируется цветовая картина мира как отдельных, так и двух или больше языков. Появление когнитологии стало толчком для всплеска работ, уделяющих большее внимание взаимосвязи языка и культуры, процессу познания человеком посредством языка окружающей действительности и процессам человеческого мышления. Такой подход требует при изучении языковой системы использования знаний различных наук. Исследования цветовой лексики на практическом материале доказывают различную интерпретацию языковых фактов в области

${ }^{1}$ В связи с этим см. работы А. Вежбицкой, Р. Токарского, В.Г. Кульпиной, Р.М. Фрумкиной, А.П. Василевича. 
зрительного восприятия цвета в различных культурах. По определению Ш.К. Жаркынбековой,

Различия обусловлены особенностями национального склада мышления, самобытностью природной среды и материальной культуры и, как следствие, неодинаковым выбором так называемых точек референции, или наиболее типичных прототипов того или иного концепта²

По мнению К. Вашаковой, цветообозначения становятся хорошим примером семантической языковой типологии, свидетельствуют о разных способах концептуализации мира отдельными языкамиㄹ.

На современном этапе развития общества взаимоотношения цвета и культуры становятся все сильнее. Особое значение цвета в обществе связано с функцией и целями, какие придают этому семиотическому знаку. Социальное пространство, в котором проявляются основные функции цвета, является также местом взаимодействия и других семиотических систем - языка, изображения, звука.

Учитывая особый интерес к цвету в современных лингвистических исследованиях, в настоящей статье мы предпринимаем попытку анализа структуры семантического поля прилагательных biaty и белый в польском и русском языках, опираясь на представленное Р. Токарским деление белого на два типа: белый квантитативный (biel kwantytatywna) и белый квалитативный (biel kwalitatywna) ${ }^{4}$.

У носителей языка значение слова предстоит не как перечень определенных семантических признаков, а как одно понятийное целое, т. е. то, что говорящий имеет в виду, употребляя данное слово. Следовательно, то, что отдельные люди думают о слове (его значении), в совокупности образует коллективное языковое сознание. Так, например, что приходит человеку в голову, когда слышат слово белый или biały? У каждого могут возникать разные ассоциации, тем не менее значительная часть из них будет совпадать. Связь признака с его конкретным носителем образует и его цветовой образец (прототип). Прототипом-инвариантом для прилагательных белый и biaty, как показывают современные словари польского и русского языков, является несомненно снег. Как полагает О.А. Михайлова,

2 Ш.К. Ж а р к ы н б е к о в а, Ассоииативные признаки изетообозначений и языковое сознание, „Вестник Московского университета. Сер. 9: Филология” 2003, № 1, c. 111.

${ }^{3} \mathrm{~K} . \mathrm{W}$ a s z a k o w a, Podstawowe nazwy barw i ich prototypowe odniesienia. Metodologia opisu porównawczego, [в:] Studia z semantyki porównawczej, nazwy braw, nazwy wymiarów, predykaty mentalne, cz. 1, red. R. Grzegorczykowa, K. Waszakowa, Warszawa 2000, c. 17.

${ }^{4}$ R. T o k a r s k i, Semantyka barw we wspótczesnej polszczyźnie, Lublin 2004. 
Современные толковые словари, хотя и не вполне последовательно, фиксируют [...] именно прототипическое значение, так как они реализуют антропоморфный принцип организации материала и предназначены отразить то представление о мире, которое характерно для среднего интеллигентного носителя языка. Этим объясняется наличие в словарной дефиниции не только фрагмента, семантизирующего признаки понятия, но также и другого фрагмента, отражающего „прототипические признаки” денотата 5 .

Теория прототипа и понимание прототипа хорошо представлены в лингвистической литературе ${ }^{6}$. Поэтому не будем их здесь описывать, а сосредоточимся на прототипах цветообозначений белый и biaty на базе словарных данных. Возникает вопрос, с помощью каких фрагментов окружающего мира категоризируется семантика анализируемого цвета; как вычленяется его прототипическое значение из определенного множества семантических признаков, являющихся их носителем. Для сопоставления прототипов прилагательных белый и biały целесообразным будет сослаться на лексикографические данные польских и русских словарей, в частности на Больщой толковый словарь русского языка под ред. С.А. Кузнецова7 и Stownik 100 tysięcy potrzebnych słów под ред. Е. Бральчика ${ }^{8}$. В обоих словарях в прямом значении лексем белый и biaty зафиксирована информация о прототипических референтах. Остальные значения образуют иерархическую семантическую сеть взаимосвязанных значений, образующих внутрисистемные отношения. Следует отметить, что лексикографические источники польского языка представляют семантику прилагательного biaty скупее по сравнению с русским языком, в котором у прилагательного белый словари отмечают больше значений. Большинство лексикографических источников польского языка фиксирует по 2 значения9.

Сопоставляя словарные статьи, можно отметить много сходств в значениях лексем белый и biaty. В обоих языках дефиниции указывают тождество десигнатов, являющихся носителем отмеченного признака, ср.: „Цвета снега, молока, мела (противоп.: чёрный)”10 и „таја̨су

${ }^{5}$ O.А. М и х а й л о в а, Лексическое значение в свете альтернативных научных парадигм, см. электронный ресурс: http://www.km.ru/referats/6905E9F347C741DC9 FA057AAB68B9987 (15.04.2015).

${ }_{6}^{6}$ См. работы Ч.Дж. Филлмора, А. Вежбицкой, Ж. Клейбера, Л. Виттгенштейна, Дж. Лакоффа, Э. Рош, И.М. Кобозевой, Р. Токарского, К. Вашаковой и др.

7 Большой толковый словарь русского языка, под ред. С.А. Кузнецова, Санкт-Петербург 1998.

8 Stownik 100 tysięcy potrzebnych stów, red. J. Bralczyk, Warszawa 2005.

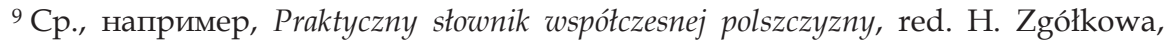
t. 1-50, Poznań 1994-2005; Uniwersalny słownik jezzyka polskiego, red. S. Dubisz, Warszawa 2006.

10 Большой толковый словарь..., указ. соч., с. 34. 
bardzo jasną barwę, taką jak mleko"11. Другие польские словари приводят те же цветовые эталоны: „о kolorze: taki jak świeży śnieg; przeciwstawny do czarnego; bardzo jasny"12; „mający bardzo jasną barwę, taką jak śnieg lub mleko"13; "taki, który ma kolor śniegu, mleka; bardzo jasny"14; „mający barwę przeciwstawną do czarnej, właściwą śniegowi, mleku itp.; bardzo jasny"15. Из представленного вытекает, что цветовыми образцами прилагательного biaty чаще всего выступают śnieg и mleko - как лучшие образцы этого признака, закоренившиеся в сознании носителей польского языка.

Применительно к прилагательному белый словари в качестве цветового образца фиксируют одни и те же объекты, т. е. снег, молоко. Кроме того, появляется также мел, не отмечаемый польскими словарями. Ср.: „Цвета снега или мела”16, „Цвета снега, молока, мела”"17. Эти первые (прямые) значения белого соотносятся с самим качеством цвета, т. е. диапазоном тона путем ссылки на объекты окружающей действительности, отмеченные данным признаком. По Р. Токарскому, такой тип значения представляет собой квалитативное понимание семантики цвета ${ }^{18}$. Данное значение экспилицируется с помощью набора прототипических референтов, таких как: снег, молоко, мел для русского языка, и снег, молоко - для польского.

Следовательно, такие элементы окружающей действительности, как снег, молоко, становятся важными составляющими понятийной структуры прилагательных biaty и белый. Следует отметить, что biaty и белый в квалитативном понимании, кроме смыслового элемента тональности, несет также сему 'светлый'. Это вытекает непосредственно из семантики прилагательного, означающего самый светлый из всех цветов. В качестве иллюстрации квалитативного употребления могут послужить следующие словосочетания: белый флаг, белый лебедь, белый мрамор, белыи изеток, biały łabędź, biała flaga, biały obrus, białe chmury. Данные коллокации указывают на компонент значения цвета (тона), в опозиции, например, к другим цветам: красный изветок, czarny tabędź, czerwona flagа и др.

11 Stownik 100 tysięcy..., указ. соч., с. 23.

12 Stownik wspótczesnego języka rosyjskiego, pod red. B. Dunaja, Warszawa 1999, c. 55.

13 Uniwersalny stownik..., указ. соч., т. 1, с. 247.

14 Praktyczny stownik..., указ. соч., т. 4, с. 201.

15 Stownik języka polskiego, указ. соч., т. 1, с. 478.

16 С.И. О ж е г о в, Н.Ю. Ш в е д о в а, Толковый словарь русского языка, Москва 1997, c. 43.

17 Словарь русского языка: b 4-x томах, под ред. А.П. Евгеньевой, Москва 19811984, т. 1, с. 78.

18 R. T o k a r s k i, указ. соч., с. $40-41$. 
Сошлемся еще на данные сравнительных словарей, которые также несут ценную информацию о наиболее стереотипных объектах сравнения. Компаративные конструкции с прилагательными белый и biaty непосредственно ссылаются на качественную характеристику тона, напр.: белый как полотно 'о чем-то абсолютно белом, белоснежном'19, biały jak śnieg 'o czymś nieskazitelnie białym', biały jak ser 'o twarzy lub zębach'20. Однако часть сравнительных оборотов реализует иной тип белого, опирающийся не на качество цвета, а на количество света (светлоту), ср.: белый как стена 'О смертельно бледном человеке', белый как мел 'Об очень бледном человеке'21, biały jak papier 'zwykle o człowieku, który zbladł, lub o jego twarzy', biaty jak ściana 'o czyjejś bladej twarzy'. Данные конструкции отражают семантику количества света в значении лексем белый иbiaty, т. е. их квантитативный элемент. Проиллюстрируем примерами такой тип белого, в котором на первый план выдвигается квантитативное значение света, ср.: белый липовый мёд, белое вино, белое мясо, белый хлеб, белая кожа, белый день, средь бела дня; w biaty dzień, biała skóra, białe wino, biate mięso. В приведенных словосочетаниях прилагательные белый иbiaty несут информацию не о семантике диапазона тона (белизне), а количестве света (светлоте).

Тем не менее, по нашему мнению, в некоторых словосочетаниях, напр. белый липовый мёд, белое вино, белый день, средь бела дня, w biaty dzień, białe wino, появляется дополнительный элемент значения. В этих словосочетениях кроме семы 'светлота' можно усматривать наличие и другого компонента значения - 'прозрачность' или 'бесцветность'. Прозрачность непосредственно связана с пространственным видением, т. е. объемным видением трехмерного пространства. Следуя далыше, можно говорить о наличии сем 'прозрачности', 'бесцветности'.

Семантика „прозрачности” выражается при характеристике пространственных объектов, так как пространственность объекта может выражаться, кроме прочего, с помощью бесцветности, прозрачности ${ }^{22}$. Поэтому к лучшим примерам объектов, обладающих данной чертой, можно причислить, с одной стороны, воду, водные объекты, жидкости, с другой - воздух. Семантика прозрачности проявляется, например, в следующих экземплификациях из разговорного и жаргонного пласта языковой системы: белая головка 'бутылка водки', или белая 'водка'23.

19 В.М. М о к и е н к о, Словарь сравнений русского языка, Санкт-Петербург 2003, с. 329.

20 M. B a ń k o, Stownik porównań, Warszawa 2004, c. 16.

${ }_{21}^{21}$ В.М. Мокиенко, Словарь сравнений..., указ. соч., с. 414.

${ }^{22}$ Y. F e d o r u s h k o v, A. N a r 1 o c h, Prolegomena do dydaktycznej prezentacji konceptu językowego w wizualizacji grafowej (na przykładzie rosyjskiego konceptu белыū), „Studia Rossica Gedanensia" 2014, nr 1, с. 189.

23 В.М. М о к и е н к о, Т.Г. Н и к и н и на, Большой толковый словарь русского языка, Санкт-Петербург 2000, с. 57, 131. 
Ср. также определение белого вина - белое 'белое вино'. Кроме того, в русской нефтяной терминологии употребляется определение белые масла со значением: 'бесцветные, прозрачные нефтяные масла, получаемые каталитическим гидрированием нефтяных фракций или очисткой масляных дестиллятов'24. Польский язык не активизировал этого типа значений, что может свидетельствовать о меньшей активности этого компонента значения у прилагательного biały.

Прежде чем объяснить „прозрачность” прилагательных белый и biaty в словосочетаниях типа средь бела дня или w biaty dzień, остановимся на исследованиях А. Вежбицкой, которая, исследуя ахроматические цветообозначения (белый / черный), обращает внимание на их семантическую близость с оппозицией съетлый/темный. Такой подход имеет много общего с универсалиями видения. По определению автора, „'видение' - это действительно универсальное человеческое понятие" 25 . Как дальше констатирует А. Вежбицкая,

...универсальное или почти универсальное различие между, грубо говоря, ночью (темным временем) и днем (светлым временем), похоже, универсальным или почти универсальным образом связано с различием или различиями в описании того, что человек видит. Грубо говоря, человек различает, и это универсально, те предметы, которые кажутся „светлыми” и „блестящими”, и те, которые кажутся „темными” и „тусклыми” (т. е. без света и без блеска) ${ }^{26}$.

Важно при этом учесть также понятие фона (окружения) - „как фундаментального структурного элемента референции при любом описании зрительного восприятия" 27. Человек вообще видит, когда предметы можно различать на определенном фоне. Ночью, когда нет света, исчезает и сам фон, конкретные объекты становятся невидимыми, черными, следовательно - фон сливается с объектами восприятия. Универсалии человеческого видения опираются на различие „между временем, когда человек видит («день»), и временем, когда он не видит («ночь»)". Впрочем, во многих языках существует деление цветов через призму понятий светлый/тёмный28.

${ }_{24}$ Ср. дефиницию термина белые масла, [в:] электронный ресурс: http://dic. academic.ru (04.08.2014).

25 А. В е ж б и ц к а я, Обозначения иъета и универсалии зрительного восприятия, см.: электронный ресурс: http://www.philology.ru/linguistics1/wierzbicka-96b.htm (22.04.2015).

26 Там же.

27 Там же.

28 См. работы: Е. Н e i d e r, "Focal" color areas and the development of color names, "Developmental Psychology" 1971, vol. 4; ее же, Universals in color naming and memory, “Journal of Experimental Psychology" 1972, vol. 93; A. W i e r z b i c k a, Znaczenie nazw kolorów i uniwersalia widzenia, [в:] Język - umyst - kultura, red. J. Bartmiński, Warszawa 1999. 
Вернемся, однако, к различию между ночью и днем. В темное время, как пишет А. Вежбицкая, люди ничего (или почти ничего) не видят, а в светлое время могут видеть, тем более различать цвета. В светлое время (день) можем различать цвета и видим черный цвет. В светлое время различаем предметы, пространство, расстояние между объектами и т. д. Ночное время усложняет процесс восприятия окружающей действительности: не различаем цвета, чувство пространства ослабевает или вовсе утрачивается в условиях всеохватывающей темноты. Ночью объекты разных цветов будут или черными (если различаются на фоне), или вовсе невидимыми. Как мы уже вспомнили, день это время, когда люди могут видеть, различать предметы, форму, цвет, светлоту / темноту. Этот способ видения наводит на мысль также некоторые ассоциации с пространственной способностью видеть объекты. Как мы уже отметили, можем тогда видеть предметы и темные, и очень темные (черные). Следовательно, такая способность видения - это пространственное видение. Различая близкие и дальние объекты, можем определить их цвет, величину и т. д. Поэтому в таких определениях, как средь бела дня, w biały dzień, можно выделить пространственный элемент значения. Условно такой тип белого назовем транспарентный белый (biel transparentna от ang. transparency - прозрачность). По нашему мнению, транспарентный белый выражает семантику пространственного признака, указывающего на возможность различать объекты в пространстве.

В понятийной сфере транспарентного белого функционирует семантический элемент, связанный с отсутствием окраски (бесцветностью), что в пространственном измерении касается понятия прозрачности данного объекта. Некоторые предпосылки наличия такого типа белого были уже предварительно намечены в статье Prolegomena do $d y$ daktycznej prezentacji konceptu jezykowego w wizualizacji grafowej (na przykładzie rosyjskiego konсерtи белый ${ }^{29}$.

Транспарентность белого становится своего рода непосредственным противопоставлением „отсутствия видения вообще”. Как указывалось, темное время - это период, когда люди ничего или почти ничего не видят. Все окружающее сливается в одно неделимое целое с меньшей или большей возможностью различать объекты, форму или цвет, так как все объекты в темное время становятся черными. В таком случае чернота лишена признака пространственности. Приведем ряд примеров, подтверждающих двухмерность черного цвета: „сzarny catun spokoju nocy okrył zmęczone oblicze...", "czarny całun okryt resztki dnia, gasząc je doszczętnie...", "Całun ciemności spowił swoim płaszczem, zginęty kształty, nie-

${ }^{29}$ Y. F e d o r u s h k o v, A. N a r l o c h, указ. соч., с. 179-208. 
przydatne nazwy” 30 . Por. przykłady rosyjskie: „И как только черное покрывало ночи накрывает такой город - в город приходит нега, расслабленность, спокойствие" (А. Афанасьев, Крушение илююзий), „Мрачное черное покрывало ночи ухнуло на город, грузно придавив крыши домов..." (В. Угрюмов, Боеи. Оборотни). На основе вышеприведенных экземплификаций можно сделать вывод, что чернота концептуализируется через призму двухмерности, т. е. в форме покрывающего окружающее пространство материала (ткани, плаща), некоторой преграды, барьера. Таким образом, в лексеме чёрный отсутствует признак пространственности, трехмерности, в отличие от лексемы белыи, в которой мы выделили транспарентное значение.

Подводя итоги сказанному, следует отметить, что семантика белого цвета довольно сложна и многопланова. В семантической структуре этого цветообозначения имеются три главных элемента значения. Кроме квантитативного и квалитативного понимания семантики цвета следует еще выделить транспарентное значение. Транспарентность непосредственно связана с семантикой прозрачности и бесцветности и реализуется в словосочетаниях, в которых прилагательные белый и biaty вступают в связь с существительными, называющими разного рода жидкости или дневное время суток.

30 Примеры почерпнуты из интернет-источников. 